\title{
ARTE, SONIDO E INTERNET: EL NET.SOUND ART FRENTE A LA EXPERIMENTACIÓN SONORA DE LAS VANGUARDIAS Y NEOVANGUARDIAS ${ }^{1}$
}

\author{
Art, sound and the Internet: net.sound art practices facing the Avant-Gardes and \\ Neo-Avant-Gardes sound experiments
}

\author{
Borja Morgado* \\ Elena López**
}

\begin{abstract}
RESUMEN
Internet está acogiendo un creciente número de obras de arte que reflexionan en torno al fenómeno acústico. Sin duda, algunas de las estrategias comunicativas resultantes de la experimentación sonora y artística del último siglo se han visto introducidas en la producción contemporánea de lo que hemos denominado net.sound art. Este término queda definido como arte sonoro online que recibe de la Red su forma y su significado, perdiendo su coherencia vital fuera de esta. Con el fin de comprender las nuevas posibilidades derivadas de la asociación arte sonoro-Internet, se ha realizado una selección y un estudio de piezas de net.sound art. Internet no solo favorece determinados comportamientos y discursos en esta práctica artística, sino que su lógica obliga a una actualización de conceptos teóricos del arte sonoro offline para su aplicación en el ciberespacio, proponiendo nuevas formas a la hora de experimentar con el fenómeno acústico.
\end{abstract}

Palabras clave: Arte sonoro, Vanguardias, Neovanguardias, Internet, net.sound art.

${ }^{1}$ Contrato (19750/FPI/15) financiado por la Consejería de Educación y Universidades de la CARM, a través de la Fundación Séneca-Agencia de Ciencia y Tecnología de la Región de Murcia.

* Facultad de Bellas Artes, Universidad de Murcia. Murcia, España. Correo electrónico: morgado@um.es

** Facultad de Bellas Artes, Universidad de Murcia. Murcia, Espańa. Correo electrónico: elena. lopez5@um.es

Artículo recibido el 05 de agosto de 2014. Aceptado el 22 de abril de 2015. 


\begin{abstract}
Undoubtedly, some of the communication strategies arisen from the sound and art experiments of the last century have been introduced in the contemporary production of what we have denominated net.sound art. This concept is defined as: sound art online that receives its meaning and shape from the Internet, losing its vital coherence outside of it. With the aim of understanding the new possibilities derived from the association sound art-Internet, a selection and a study of net.sound artworks have been made. The Internet not only favours certain behaviours and discourses in that art practice, its own logic and its own internal mechanisms also force to update some theoretical concepts from the sound art offline to apply them in cyberspace, and provide new ways to experiment the acoustic phenomenon.
\end{abstract}

Keywords: Sound art, Avant-Gardes, Neo-Avant-Gardes, Internet, net.sound art.

\title{
1. INTRODUCCIÓN
}

Desde las Vanguardias Históricas de principios del siglo XX y sus incesantes ejercicios para lograr una pérdida de especificidad de las diferentes disciplinas artísticas, muchos artistas visuales comenzaron a trabajar el sonido como material experimental, escultórico y performativo. En sus prácticas se favorecía una anulación de la partitura y de la linealidad discursiva de la música -por ejemplo en los ruidismos del Dadá- en busca de cómputos con unidades discretas de sonido -hacia la segunda mitad del siglo XX con-, por ejemplo, el movimiento Fluxus. Tras una época prolífica en cuanto a producción, exhibición y teorización de lo que, posteriormente, en los años 90 empezaría a presentarse en los diccionarios especializados como Sound Art, la aparición y expansión de los ordenadores supuso un punto de inflexión para aquellos interesados en el fenómeno acústico. Los artistas e investigadores del sonido que trabajan con ordenadores han asumido una portentosa espacialización del tiempo sonoro mediante el uso del dispositivo pantalla. El fenómeno de "desflecamiento" sobre el que teoriza Theodor Adorno (1966) -entendido como disolución de fronteras entre las distintas artes- y posteriormente desarrollado como "campo expandido" por Rosalind Krauss (1979), se ve notablemente agudizado en un momento en el que la noción de "sonido visual" se pone en práctica cotidianamente.

Si bien esta pantalla dinámica y de inmersión hereda del cine propiedades espaciales como la movilidad del encuadre, también nos proporciona nuevas capacidades temporales mediante la gestión de datos de distinta naturaleza en tiempo real (Manovich, 2001). Esta característica, en consonancia con lo que se ha 
denominado "nuevas tecnologías multi-pantalla", hacen referencia a uno de los ejes centrales de esta investigación: Internet como espacio de conexión y sincronización de datos, dispositivos y usuarios. Así, nuestra intención es la de estudiar las confluencias entre la pantalla en tiempo real (la pantalla-Internet) y las experimentaciones sonoras contemporáneas. ¿Cómo interactúan? ¿Introduce Internet nuevas dinámicas en la producción de arte sonoro? ¿Existen, asimismo, analogías en las trayectorias de este arte en el mundo físico y en el virtual? Es fundamental matizar que no nos centraremos en obras dispuestas en el espacio material que hayan utilizado la Red como mera herramienta a lo largo de su proceso de construcción, sino que nuestro foco de análisis residirá en aquellas producciones sonoras que habitan en un Internet que les confiere tanto estructura como significado y que no tienen una existencia posible fuera de la Red (net.sound art).

\section{CIBERESPACIO Y ARTE SONORO}

El ciberespacio es entendido hoy como una pantagruélica base de datos creciente. Cabe destacar que en sí mismo encierra una paradoja (ciber) ontológica que lo define tanto como actividad, conexión, y como contenedor fluido y voluble de esa misma actividad. Por ello, no es de extrañar que las prácticas artísticas en su seno hayan tomado forma o bien de transmisiones en tiempo real o de colecciones de datos por las que navegar, hecho del que no ha quedado al margen el net.sound art. Dado que la interfaz a través de la cual experimentamos el espacio virtual tiene un marcado carácter oculocéntrico, la lógica del medio hizo que las primeras webs artísticas careciesen de elementos sonoros o, en el mejor de los casos, utilizasen el sonido como ingrediente secundario y casi ambiental. De la misma manera que en el cine se requirió de un proceso de incorporación del sonido a la imagen (música en directo, música grabada, etc. hasta alcanzar una perfecta sincronización entre imagen y guion), las distintas interfaces de la Red han necesitado de su propio tiempo de sincronización. Es de vital importancia comprender que el arte sonoro aboga por un predominio de lo sonoro sobre lo visual, lo que en un medio como Internet se convierte en una ardua tarea. No obstante, se trata de un predominio conceptual, y no tanto "físico" (valor difícilmente cuantificable). Así pues, los experimentadores sonoros en Red han dado rienda suelta a su ingenio logrando ofrecernos interesantes obras de net.sound art.

A lo largo de nuestro trabajo de campo consistente en rastrear el ciberespacio para localizar y analizar piezas de estas características, nos percatamos de que, al igual que ocurre en las artes visuales de la Red, no se puede entender Internet como una burbuja aislada. Es decir, aun ofreciendo novedosas posibilidades con respecto al espacio físico (conectividad, ubicuidad, hipertextualidad, etc.), las distintas 
manifestaciones artísticas que se desarrollan en su seno siguen aplicando lenguajes del arte offline del siglo XX. Con el fin de ilustrar esta tesis, hemos realizado una selección de piezas de net.sound art sobre las que, a partir de ahora, proyectaremos sinonimias con piezas de arte sonoro offline, al tiempo que especificaremos las nuevas capacidades adquiridas mediante su gestación, asentamiento y vida en la Red.

\subsection{Instrumentos inventados y arte radiofónico: Daisyphone y Locustream Audio Tardis}

En los albores de las Vanguardias Históricas, muchas de las primeras prácticas que emprendieron una tendencia de lo visual hacia lo sonoro se desarrollaron al amparo del Futurismo italiano de principios del siglo XX. De esto, son paradigmáticos los instrumentos inventados y el arte radiofónico.

En el primero de los casos, se trata de nuevos objetos construidos con el propósito de producir sonidos poco convencionales con respecto al discurso musical tradicional. Tuvieron especial relevancia los denominados intonarumori o entonaruidos (1913) del compositor Luigi Russolo. Estos estaban compuestos por cajas de madera de distintos colores con dispositivos mecánicos en su interior que, al activarse, reproducían sonidos que recordaban al sector industrial (motores, trenes, etc.) a través de unos altavoces.

Actualmente, debido al auge del sonido digital y al desarrollo de aplicaciones interactivas, no es difícil acceder a programas de complejidad variable que, a modo de instrumentos inventados, nos ofrecen una enorme variedad de sonidos y herramientas para que experimentemos con el fenómeno acústico. Ejemplo de esto son: Konkreet Performer (Konkreet Labs, 2011) para Ipad y Iphone, Samplr (Marcos Alonso, 2012) para Ipad, Sona (Ruslan Gaynutdinov, 2012) para Ipad, Borderlands (Cristopher Carlson) para Ipad y publicitado en el festival Sonar de Barcelona 2012, etc. No obstante, la inmensa mayoría de estas aplicaciones tan solo utiliza Internet como un catálogo donde poder encontrar un producto que comprar y descargar. Una vez instaladas, su uso no suele estar vinculado a la Red.

Para que Internet tenga un papel fundamental en el modus operandi y desarrollo de la propia experimentación sonora del usuario, la Red debe ofrecer una experiencia que cobre vida en, por y para el propio ciberespacio, y no verse reducida a mero lugar expositivo. Bajo estos parámetros de búsqueda se ha localizado Daisyphone (Nick Bryan-Kinns, primera versión en 2003) (www.daisyphone.net), una aplicación Java diseńada tanto para ordenador, como para Iphone y Ipad. A diferencia de las aplicaciones anteriormente mencionadas, Daisyphone nos permite acceder a su contenido en modo "usuario único" o "multi-usuario", permitiendo generar piezas en directo con personas, conocidas o desconocidas, de distintas geografías. Así mismo, ofrece la posibilidad de que todos los participantes puedan 
añadir elementos sonoros, corregir las aportaciones de otros, así como escribir comentarios o dibujar en la propia interfaz sonora. Al comenzar, la pantalla muestra la abstracción geométrica de una margarita, con un disco central y círculos más pequeños a su alrededor que van formando los rayos que constituyen los pétalos. En esta interfaz, sin mediar intervención alguna, a cada usuario se le asigna un color, los tipos de sonido a escoger vienen representados por distintas figuras geométricas básicas, el tono de las notas se intensifica conforme nos acercamos al disco central, el volumen se traduce en la mayor o menor saturación del color, etc. Pero, además del lenguaje visual que codifica el lenguaje sonoro, la pantalla donde acontece todo el proceso creativo funciona como una pizarra donde podemos introducir el lenguaje textual escribiendo manualmente cualquier comentario. La estructura de esta aplicación fomenta, así, la generación de ambientes sonoros sociales e improvisados, con finales impredecibles frente a la producción de composiciones cerradas y premeditadas. Para ello, se desarrolla una colaboración basada en relaciones horizontales en las que todos tienen las mismas responsabilidades, y, por tanto, en la práctica de lo que Pierre Lévy denominó "inteligencia colectiva" (1997). Es una pieza que surge de la conexión, de la sociabilización virtual a través del sonido, pero que al mismo tiempo permite compartir y descargar todas las improvisaciones resultantes, sumando nueva información, nuevos datos, a la red de redes. Se trata, pues, de una aplicación muy completa cuya forma y objetivo forman parte de la propia estructura de posibilidades que es Internet, manifestándose a través de la cooperación e interactividad, del compromiso por desarrollar proyectos sonoros multi-usuario y de las producciones improvisadas que circulan por la arquitectura hipertextual del ciberespacio.

Si bien la sociabilización y el registro de nuevos datos son actividades propias de la Red, cabe destacar que no todas las piezas de net.sound art tienen por objetivo ofrecer este tipo de experiencias. Más en consonancia con el arte radiofónico de Fortunato Depero se encuentra la pieza Locustream Audio Tardis (Locusonus, 2006) (http://locusonus.org/tardis/). Depero, en su libro Liriche Radiofoniche de 1934, o Lírica Radiofónica, publicó cinco piezas concebidas para ser emitidas por radio cuyas intenciones eran, entre otras, las de reactualizar dicho medio de comunicación, desacreditar el tipo de emisiones que en él eran habituales y proponer "emisiones espaciales" mediante las cuales el oyente pudiese viajar a través del sonido a cualquier lugar: calles, barcos, etc. (VVAA, 2004). Locustream Audio Tardis hace referencia a esas "emisiones espaciales". Se trata de una red de micrófonos abiertos veinticuatro horas repartidos por distintos países del mundo y en distintos espacios: cerrados y abiertos, públicos y privados. Al poco tiempo de entrar en la web se puede oír el sonido de un lugar distante y, a los pocos minutos, ese lugar enmudece para dar paso al sonido de otro espacio, cambiando de una ciudad a otra de forma aleatoria. La interfaz es extremadamente sencilla. En la 
pantalla en negro solo irrumpe una frase en gris oscuro que informa sobre el día actual, la hora local en la que se está emitiendo, el país de emisión, la ciudad y el nombre o pseudónimo del colaborador altruista que ha participado colocando el micrófono en dicho espacio y conectándolo a esta red. Apenas hay estímulo visual, solo experiencia sonora. En esta ocasión no hay un registro final, no hay un menú donde seleccionar opciones, no hay una interactividad directa entre los oyentes. Por el contrario, la información fluye sin cesar esperando a ser oída. Voces de todo el mundo se suceden, el tráfico, la lluvia, niños que juegan, puertas que se abren y cierran en el mismo instante en el que lo estamos escuchando pero a kilómetros de distancia. Sonidos que en el mismo momento en el que se producen dejan de existir, pero que en el momento de la escucha no necesariamente quedan aislados (mediante el uso de auriculares), sino que pueden coexistir con los ruidos del espacio físico y tiempo presente del oyente. La pieza no hace registros que luego clasifica, sencillamente es un flujo de información continuo que muestra instantes irrepetibles y que lleva ocho años retransmitiendo la vida acústica de distintos espacios. A la hora de enfrentarnos a la obra, nuestras posibilidades varían desde la escucha para interactuar con la pieza realizando una especie de viaje mental, hasta una participación más activa instalando un micrófono en un espacio cercano que actuará de ventana auditiva para el resto de la comunidad virtual.

En consonancia con este tipo de obras, nueve años antes de la Lírica Radiofónica de Depero, el director de cine vanguardista soviético Dziga Vertov, interesado en el Futurismo, publicó en 1925 su manifiesto Radiopravda o Radioverdad en el que exponía su intención de registrar sonidos de forma improvisada en espacios de trabajo que luego emitiría por radio para fomentar una conexión sonora, una comprensión auditiva, entre todo el proletariado mundial (VVAA, 2004). En ese intento de conectar a personas repartidas por todo el mundo a través del sonido y de que se puedan comprender entre ellas a través de la vida sonora de sus distintas geografías, este manifiesto establece otro antecedente para Locustream Audio Tardis. No obstante, cabe destacar que este último introduce novedosas propiedades relativas al uso de Internet. Locustream Audio Tardis elimina la decisión de dónde registrar el sonido y qué sonidos emitir. Por un lado, los espacios emisores dependen de los colaboradores y, por otro, no existe un montaje sonoro sino que el sonido acontece en tiempo real. Se trata de una red viva, dinámica, que puede crecer y disminuir según la decisión de sus usuarios que pueden tanto poner micrófonos nuevos como quitar antiguos.

\subsection{El collage sonoro: In b flat 2.0}

Actualmente, gracias a la abundante oferta de sonidos digitales y a la enorme variedad de herramientas que posibilitan su registro y edición, trabajar 
este material a modo de collage (reciclar, cortar, pegar, voltear, acelerar, superponer, recomponer, etc.) resulta bastante sencillo. Sin embargo, este proceso que hoy es habitual, no lo era en absoluto en la primera mitad del siglo XX donde comenzaron a brotar sugerentes pruebas sonoras relacionadas con esta técnica. En 1930, el cineasta experimental Walter Ruttmann, interesado en cómo el público percibía el sonido, produjo la primera película sin imágenes, Wochenade, que significa fin de semana. Esta se ha considerado como la primera película documentada que utilizó únicamente medios electrónicos (James, 1986). Sobre su cinta cinematográfica no se grabó ninguna imagen. Tan solo se utilizó la parte de la banda sonora para plasmar un collage de sonidos que representaban un fin de semana en Berlín. Al principio, se podían escuchar lugares de trabajo con mucho estruendo de fondo, pero conforme se avanzaba por sus once minutos y medio de duración, iban apareciendo personajes, diálogos, instrumentos, silencios, voces cantantes, etc. Se ha considerado que, en esta práctica de aislamiento de sonidos reales y cotidianos, existe un precedente de la Música concreta de Pierre Schaeffer (Robert, 2007), el cual, en 1948, emitió por radiodifusión francesa Études aux chemins de fer o Estudios sobre los railes, una amalgama de ruidos de locomotoras, silbidos, vapores liberándose, etc. grabados en la Estación de Batignolles de París. Con este tipo de prácticas, Schaeffer iniciaba el movimiento de Música concreta anteriormente citado en el que defendía la utilización de sonidos-ruidos ya existentes, concretos, como objetos sonoros, eliminando sus significados para hacer prevalecer su interés musical, su ritmo, tono, etc. Para la elaboración de sus teorías, Schaeffer estableció diferentes tipos de escucha, de entre los que propuso la "escucha reducida", una escucha poco habitual que consiste en recibir el sonido como un objeto "bruto", sin causas ni valores, como si el propio sonido fuese ya pensamiento y no hubiese que traducirlo, definirlo ni atribuirle característica alguna, solo sonido (Schaeffer, 1988). Poco después de Études aux chemins de fer, el compositor francés empezó a acelerar, retardar y solapar los sonidos que iba recogiendo para sus nuevos collages. De forma paralela, entre 1939 y 1952, el compositor y teórico musical John Cage, produjo sus Imaginary Landscapes, Paisajes Imaginarios, un conjunto de cinco experimentos cimentados en el collage sonoro. En su Paisaje Imaginario $n^{\circ} 4$ (1951), Cage actuó como director de orquesta para un grupo de veinticuatro concertistas en el teatro McMillin de la Universidad de Columbia en New York. Los concertistas se dispusieron sobre el escenario en parejas, manejando cada una de ellas una radio portátil. Cuando Cage marcó el inicio de la actuación los performers empezaron a hacer sonar las radios, cambiando progresivamente las frecuencias y el volumen (Worby, 2009). Se generó así un collage de sonidos electrónicos impredecible proveniente de las doce radios en escena. Otro ejemplo fue Paisaje Imaginario no5 (1952), diseñado para la coreografía Portrait of a Lady (Retrato de una dama) de Jean Erdman, donde se combinaron fragmentos sonoros 
que provenían de cuarenta y dos discos de jazz distintos.

En la actual cultura de la convergencia (Jenkins, 2006) en la que recibimos continuos estímulos audiovisuales de las distintas plataformas mediáticas, muchas de las composiciones audiovisuales que inundan diariamente nuestro espacio son versiones actualizadas de aquellos collages. Tan solo entrando en Internet nos sumergimos entre millones de bases de datos digitales de las que poder extraer material sonoro de distinta procedencia. Si bien existen exitosos bancos de sonidos online como SoundCloud, no es necesario acudir a un banco especializado como este para difundir, escuchar o recolectar sonidos. Plataformas audiovisuales mucho más masificadas como YouTube y Vimeo también son provechosas fuentes sonoras. En el año 2009, el músico Darren Solomon realizó un experimento musical colaborativo ayudándose de YouTube para su proceso de realización y resultado final. Esta obra titulada In B Flat 2.0 (http://www.inbflat.net/) es un collage audiovisual que, en la interfaz de su web, se dispone como una cuadrícula de cuatro líneas por cinco columnas que ordenan veinte vídeos de YouTube diferentes. Para la selección de dichos vídeos, Solomon, sin duda inspirado en las prácticas del movimiento Fluxus, (introducido en Norteamérica principalmente por Cage), publicó en su blog unas reglas para este proyecto, invitando a cualquier persona a participar en él. Algunas de sus directrices decían:

Canta o toca un instrumento en Si bemol mayor. Las texturas flotantes simples funcionan mejor [...] Deja un buen silencio entre frases.

Graba en un entorno tranquilo, con el menor ruido de fondo posible.

Espera unos 5-10 segundos para empezar a tocar.

La longitud total debería ser de entre 1 a 2 minutos [...]

Tras subir el video a YouTube reprodúcelo junto con otros videos de la página para comprobar que el volumen coincide (Kirn, 2009).

Si bien el blog de Solomon está primordialmente dirigido a músicos, esta invitación incluía a cualquier interesado. Con todo el material que fue recibiendo a través de YouTube, Solomon realizó una selección y la presentó en esta especie de mosaico que da forma a la obra final. Cada vídeo contiene una melodía, un instrumento y un intérprete distintos. Cuando un usuario cualquiera se encuentra con esta pieza, decide qué vídeos reproducir y cuáles no, su orden, el volumen de los mismos, en qué momento clicar sobre el play o pause para ir combinando las sonoridades de unos y de otros, superponiendo las capas de sonido, jugando a componer. Solomon ideó el proyecto, lo propuso y con la ayuda de los habitantes del ciberespacio elaboró una fuente de material audiovisual concreta. Sin embargo, es el usuario el que genera la música, el que "concluye" el proyecto con cada uno de sus collages personales. El usuario se convierte en los veinticuatro concertistas 
de Imaginary Landscape $n^{\circ} 4$ de Cage, modificando las variables que le ofrecen los distintos vídeos de YouTube, al igual que aquellos lo hacían con las de la radio. In $b$ flat 2.0 se ha originado en la Red, valiéndose de espacios denominados 2.0 (en los que cualquier usuario, experto informático o no, puede generar y difundir contenidos) como un blog y YouTube, siendo el resultado de una primera cibercolaboración en su fase de gestación y de una segunda que se presenta ilimitada por parte de los usuarios que estimulan con su actividad el mecanismo que da vida a la obra.

\subsection{Esculturas e instalaciones sonoras: Actualizaciones semánticas para el arte de Internet}

A partir de la década de los años cincuenta se extendió la práctica de lo que se ha denominado escultura sonora. Esta se entiende como una pieza cuyo elemento principal es el sonido y que posee características objetuales que le permiten estar en un espacio u otro sin que se vean alteradas sus propiedades conceptuales. Se trata de una práctica independiente del lugar de exposición. Es decir, son piezas non site-specific, en contraposición a las instalaciones site-specific diseñadas para una localización única que recibieron esta nomenclatura a partir de los estudios de las críticas Catherine Howett (1977) y Lucy Lippard (1977) en la década de los setenta.

Ante estas características, cabe preguntarse: ¿Es Internet un espacio que pueda aceptar los términos de una "(ciber) escultura sonora"? Como se apuntaba con anterioridad, cuando hablamos de net.sound art, nos referimos a cualquier obra de arte sonoro que únicamente tenga sentido en el espacio virtual, y que por tanto, en un intento de manifestarse fuera de la Red, perdería su coherencia vital. Es decir, Internet es el único espacio posible para su supervivencia, por lo que podríamos afirmar que todo net.sound art es site-specific, poseyendo características propias de la instalación. No obstante, estas circunstancias pueden estudiarse desde otro punto de vista. Internet también puede ser entendido como un espacio de uso público donde es la actividad de sus habitantes la que va transformando el sentido de este, como si de la plaza de una ciudad se tratase. Sin embargo, a diferencia de una plaza pública, los habitantes del ciberespacio no solo modifican el sentido de ese espacio, sino que también modifican constantemente su estructura, añadiendo, eliminando, versionando, apropiándose de información, y lo que es más habitual, estableciendo millones de nuevos vínculos y generando nuevos caminos. Si se hace primar esta concepción de Internet, se percibe que una de sus características específicas es, paradójicamente, la inespecificidad de su configuración, su estructura inestable. Su propia existencia es una acumulación de distintas versiones de sí misma que son potencialmente ilimitadas. Internet es, por tanto, un espacio mutable y líquido. ¿Se podría, entonces, hablar de arte sonoro de Internet como de 
una instalación site-specific, o, debido al continuo cambio de escenario se volvería a los planteamientos de la escultura sonora? Sin duda, Internet es un espacio que impone su propia lógica. Así, las manifestaciones artísticas que alberga parecen vapulear continuamente esos conceptos propios al espacio offline.

En efecto, el net.sound art no tiene cabida fuera del ciberespacio, pero este último ni puede geolocalizarse ni está confinado en un lugar concreto. Para hacer referencia a ese fluir del espacio en el que estas piezas flotan y se sumergen, y que precisamente les confiere propiedades particulares, deberíamos actualizar nuestro lenguaje y adaptarlo al medio en cuestión. Por ello, en este artículo se propone el término site-flowing para todas aquellas piezas sometidas a las condiciones conceptuales y espaciales específicas de Internet, reforzando ese continuo "fluir" al introducir el estado durativo del gerundio (en inglés, terminación -ing). De esta forma no se hace referencia a un cambio radical de un estado a otro, o de un espacio a otro, sino a unas transformaciones progresivas y potencialmente infinitas.

\subsubsection{The listening machine}

A la hora de establecer un antecedente de arte sonoro offline para la pieza The listening machine (Peter Gregson; Daniel Jones, 2012-2013) (http:// thelisteningmachine.org/) se encontraron sólidas concomitancias entre esta y Tour Spatiodynamique et Cybernétique, en castellano Torre espacio-dinámica y cibernética (1955) diseñada por el que se ha erigido como padre de la escultura cibernética y la escultura en tiempo real, Nicolas Schöffer. Esta pieza era una gigantesca torre metálica de cincuenta metros de altura con sensores que medían distintos factores ambientales sobre los que influían las personas próximas a la obra: luz, sonido, velocidad y frecuencia de movimientos cercanos, entre otros, favoreciendo una interacción espontánea en la que cualquiera podía participar (interactividad alta aunque sujeta a la presencia corporal). Los datos recogidos eran traducidos inmediatamente en sonidos inéditos que se retransmitían a través de más de doce amplificadores que recubrían toda la estructura. Para el desarrollo de esta pieza se requirió de la colaboración del ingeniero Jacques Bureau y del compositor de música concreta Pierre Henry, que trabajaron bajo las directrices de Schöffer (Centre Ressources Labomedia, http://wiki.labomedia.org).

Por su parte, The listening machine es una producción de net.sound art en la que participaron Daniel Jones, investigador que trabaja en la relación entre ciencia, arte y dinámicas sociales, Peter Gregson, violonchelista y compositor, y la Britten Sinfonia. Esta obra, que se pudo disfrutar en transferencia continua de mayo de 2012 hasta enero de 2013, captaba ciertos "factores ambientales" de la Red, en este caso, flujos de información virtual sobre los que determinados habitantes del ciberespacio podían influir. Si bien The listening machine no podía registrar 
la temperatura de la Red, ni su luz, ni determinar un perímetro geográfico de actuación para sus usuarios, sus autores demarcaron la actividad de quinientos usuarios ingleses de Twitter como espacio de intervención (participación directa reducida a quinientos usuarios), y establecieron como variables la frecuencia de sus tweets, la temática de los mismos y su carácter optimista, neutral o pesimista. Estos datos dinámicos serían los que, al igual que ocurría en la escultura de Schöffer, determinarían la producción de ambientes sonoros impredecibles y en tiempo real. Si en la obra del artista húngaro el punto de reunión era el emplazamiento de la torre, en el caso de The listening machine era Twitter donde se generaba la actividad de esos usuarios seleccionados y que al instante se podía disfrutar en forma de sonido experimental en una web externa. Durante los nueve meses que esta pieza estuvo activa, el resto de la comunidad virtual debía limitarse a su escucha "radiofónica" que se podía acompañar de la visualización de unos gráficos que mostraban, en directo, los cambios de valor en las variables seleccionadas. Desde enero de 2013, esta web es una fonoteca donde han quedado registrados y clasificados los fragmentos de la improvisación sonora resultante, ofreciendo una interactividad de tipo arbóreo. Es decir, el usuario puede decidir cómo navegar por una serie de archivos sonoros que pertenecen a un menú cerrado. De la pieza en streaming ha quedado una base de datos por la que pasear.

Cabe destacar que, en ambas obras, esa traducción instantánea de datos cuantificables a distintas capas sonoras era el resultado de operaciones matemáticas que hacen de la pieza un sistema autónomo productor de sonidos. Este tipo de procesos denominados "generativos" se caracterizan por utilizar medios mecánicos (como por ejemplo el ordenador) y procesos algorítmicos para la obtención de resultados orgánicos. Las bases de datos dinámicas de las que extraen información son, en el primero de los casos el mundo físico, y en el segundo, el espacio virtual, perteneciendo cada una a los espacios donde las piezas habitan. Se trata de acciones de interpretación de datos que tienen un inicio y un fin (desconexión de "la máquina") y de las que pueden quedar registros como huella de su existencia. Metafóricamente hablando, podríamos hablar de performances algorítmicas. Ya no se trata de que un individuo realice una acción de duración determinada, ya que los viandantes que paseaban cerca de la obra de Schöffer, o los twiteros participantes en The listening machine, seguirán con su actividad, se esté o no desarrollando paralelamente el proyecto artístico. El protagonismo recae sobre el algoritmo que, cuando deja de traducir, provoca la finalización de la actividad artística.

\subsection{El paisaje sonoro: Sonic Walkie y Stereopublic: Crowdsourcing the Quiet}

A partir de los esfuerzos de Pierre Schaeffer por fomentar la escucha de todo aquello que nos rodea, el compositor canadiense Murray Schafer acuñó, a 
finales de los años sesenta, el término Soundscape (Paisaje sonoro) para referirse a los sonidos que inundan nuestro entorno como los causados por la naturaleza (viento, lluvia, animales, etc.) y el hombre (tráfico, pisadas bajando escaleras, etc.). En las prácticas artísticas relativas a los Paisajes sonoros se incentiva una reflexión de nuestra atmósfera audible a partir de grabaciones que no se suelen modificar intentando captar esa realidad acústica que nos envuelve y que en muchas ocasiones desatendemos. Pierre Henry, en 1984, sin duda inspirado por la obra Wochenade de Ruttmann, realizó la pieza La ville. Die Stadt: Metropolis Paris, una serie de fragmentos sonoros de duración variable recogidos en París, definidos y titulados con ejemplos como: péndulo, perros, interior, juegos, puertas, etc. y que en su conjunto forman una especie de mapa acústico de la capital francesa.

A la hora de experimentar el Paisaje sonoro a través de Internet, los artistas nos han ofrecido formas muy diversas. Por un lado, podemos volver a hacer referencia a la radio de Locustream Audio Tardis que, si bien incentiva la escucha de distintos entornos acústicos, no trabaja el aspecto de patrimonio histórico-sonoro mediante la grabación, documentación y clasificación de los sonidos que emite. Sin duda, la forma más básica de introducir el Paisaje sonoro en la Red es la de utilizar esta última como espacio donde albergar y consultar registros realizados durante un periodo de tiempo ya concluido, a modo de menú cerrado donde seleccionar opciones. Un ejemplo de ello sería la puesta en línea de La ville. Die Stadt: Metropolis Paris para una mayor difusión a través de la Red. Sin embargo, teniendo en cuenta las capacidades del medio, parece lógico que estas bases de datos deban mantenerse activas, al menos durante un periodo de tiempo, recibiendo material sonoro de forma indefinida. Con el fin de mostrar los beneficios derivados del uso de la Red en las prácticas del Paisaje sonoro, se han seleccionado dos piezas de net.sound art que integran el dinamismo del medio en sus estrategias vitales, aunque a niveles muy diferentes.

En primerlugar, se hace referencia a Sonic Walkie (Andrea Pazosy Edu Comelles, 2010) (http://andreapazos.com/sonicwalkie/index.html), obra seleccionada en la categoría de Net.art para el festival In-Sonora VII de Madrid. Esta pieza, se centra en los paralelismos sonoros existentes entre las distintas ciudades, ejemplificándolos mediante conexiones temático-acústicas entre Valencia y Manchester, localidades donde habitan los autores. Ambos, mensualmente, fueron estableciendo un tema en relación con un espacio urbano cualquiera: pájaros, café, transporte público, parque infantil, gol, etc. de la misma forma que Henry clasificó sus objetos sonoros y descriptivos del París de 1984. Una vez hecho esto, en un lugar concreto de sus respectivas ciudades, llevaban a cabo una grabación de, aproximadamente, un minuto, que actuaría a modo de definición sonora del tema predeterminado. Con el fin de resaltar las simetrías sonoras y conceptuales, los dos archivos se unirían posteriormente, reproduciéndose así de forma sincrónica, aunque saliendo, cada una 
de las grabaciones, por un canal de audio distinto. La verdadera mezcla se produce, por tanto, en el propio acto de la escucha en el que los distintos sonidos se funden en un único espacio, haciendo que el cerebro reciba toda la información al mismo tiempo.

La web del proyecto se estructura en torno a un listado de los títulos de las distintas grabaciones. Al hacer clic sobre uno de ellos se abre un desplegable que contiene la pista de audio compartida a través de SoundCloud, así como dos imágenes enfrentadas que corresponden a los emplazamientos donde se desarrollaron las grabaciones. Estas imágenes son dinámicas y están vinculadas con otra base de datos. Al pinchar sobre ellas se abre una nueva ventana en la que aparece la dirección de esos lugares en Google Maps o Google Street View, pudiendo visitarlos virtualmente.

Tras más de un ańo y medio de actividad, en la que esta base de datos fue creciendo periódicamente hasta alcanzar veintiuna pistas sonoras, el proyecto finalizó con la publicación de la pista número veintidós titulada Exquisite Corpse (Cadáver exquisito) que contiene la suma de todas las pistas anteriormente publicadas, una tras otra. Durante la escucha de estas, el oyente debería dejar de diferenciar el espacio de los sonidos, las dos ciudades, haciendo que de los distintos elementos nuestra mente genere una única imagen sonora- al igual que ocurría visualmente con los cadáveres exquisitos del Surrealismo -que incluya todos los parques infantiles, todos los cláxones, todos los cantos de gol, todas las ciudades, etc. El espacio queda unificado por el sonido y por el medio de Internet, que elimina fronteras produciendo una nueva (ciber) topografía sin horizontes, caracterizándose por una acusada tendencia globalizadora. Asimismo, la conexión espacial que se deriva de estas pistas fomenta, a su vez, una conexión personal, el entendimiento entre individuos distintos a través del sonido, exactamente aquello que buscaba Vertov en su Radioverdad pero, en esta ocasión, sin connotaciones políticas.

A pesar de la finalización del proyecto, esta experiencia se puede revivir a través de los registros que dan testimonio de la acción y que permiten un paseo por la arquitectura hipertextual de su interfaz que vincula los elementos sonoros y visuales.

La segunda obra de net.sound art a la que se hace referencia en este apartado es Stereopublic: crowdsourcing the Quiet (Jason Sweeney, 2012-) (http://www. stereopublic.net/) premio TED City 2.0 2012. Esta pieza surgió con la intención de generar una red dinámica para compartir espacios de sosiego en grandes ciudades, superando actualmente las ochocientas aportaciones que hacen referencia a más de dieciocho ciudades como Los Ángeles, Vancouver, Londres, Barcelona, etc. Aplicando estrategias de representación cartográfica, mediante el uso de Google Maps, Sweeney propone un gran mapa en el que cualquier persona puede 
geolocalizar aquellos espacios que conoce y que suponen una pausa en la ajetreada vida acústica de la urbe. Debemos tener en cuenta que, en el panorama artístico, el estudio tanto del silencio como parte del sonido, como de la imposibilidad de obtener un silencio absoluto, es algo habitual desde la pieza 4'33" de John Cage (1952) habiendo influido en el discurso de artistas de la magnitud de Joseph Beuys (en, por ejemplo, Infiltration homogen für Konzertflügel, Infiltración homogénea para piano de cola, 1966) y Marina Abramovic (en Sound Environment White, 1972, de la que no se ha encontrado una traducción oficial al castellano, pero que en su traducción literal significa Ambiente sonoro blanco) (Gómez, 2012).

En la obra Stereopublic, además de localizar los espacios de tranquilidad auditiva, el usuario puede añadir imágenes y pistas de audio de los mismos, así como conocer el camino para llegar a estos desde cualquier ubicación. Mediante esa actividad denominada file-sharing (compartiendo archivos), se va tejiendo una red de datos de naturaleza dispar cuyos vínculos son las pausas del ritmo urbano. Así, este mapa adquiere una vida social que va moldeando nuevas formas de comprender el espacio, actuando sobre él, utilizando la multitud como fuente de contenidos, proporcionando una estructura abierta en la que cada nueva aportación repercutirá en la experiencia del resto de usuarios. En este intento por encontrar espacios tranquilos existen ciertas relaciones con los ideales de los flâneurs baudelerianos en contra de los ritmos urbanos del París moderno y con las derivas propias de la Internacional Situacionista de las que resultaban mapas denominados psicogeográficos. Asimismo, la interfaz de Stereopublic es un mapa subjetivo a través del cual se desarrolla una reinterpretación psicológica del entorno urbano, aunque su característica más importante y determinante es su dimensión social.

Cabe destacar, que el autor de esta pieza no se ha limitado a la producción de este proyecto para, una vez lanzado, desvincularse y dejar que toda la actividad se derive de otros usuarios. Sweeney elige espacios señalados por otro usuario, y utiliza la pista de audio que se le ha vinculado para realizar breves composiciones sonoras que, a su vez añade a la descripción del lugar en cuestión. De esta forma, cualquier usuario de la Red puede entrar en la web del proyecto e ir paseando por espacios silenciosos seńalados por todo el mundo, esparcidos por su geografía, observando las imágenes fotográficas, escuchando pistas de audio grabadas en dichos emplazamientos, escuchando reinterpretaciones sonoras de las mismas y realizando un paseo mental e hipertextual que ofrece rutas alternativas a la de los paseos físicos. El movimiento físico es reemplazado por flujos electrónicos que tienen repercusiones en el ciberespacio, y que afectan también al cuerpo del usuario de forma bisensorial: oído y vista. La cantidad de posibilidades y de información que nos ofrece, y que va en aumento, nos permite perdernos en paseos sin rumbo predeterminado, en los que vamos decidiendo sobre la marcha, el tiempo que le 
dedicamos a cada nuevo enlace, a cada nueva información.

\section{CONSIDERACIONES FINALES}

Muchas de las producciones de arte sonoro contemporáneo han encontrado en Internet un espacio habitable de ricos recursos. El medio es capaz de conferir a cualquier pieza, on y offline, un espacio donde acumular registros, así como otorgarle una mayor y eficaz difusión. No obstante, las obras que nacen en el propio medio y cuyos tiempos de vida solo pueden transcurrir en el mismo, adquieren nuevas aptitudes conceptuales y estructurales. En lo relativo al arte sonoro de Internet o net.sound art, se le atribuye un carácter experimental así como connotaciones discursivas en torno al propio medio que le da forma. Por un lado, si bien Internet no es ya un medio recién llegado y desconocido, su continuo desarrollo, que le dota incesantemente de nuevas posibilidades, le otorga esa condición "experimental", encontrándose en una fase de prueba indefinida en la que su constante progreso impide la llegada de su versión última. Por otro lado, el net.sound art siempre desembocará en un ejercicio tautológico mediante la evocación de reflexiones alrededor del medio que da vida, configuración y significado a la propia pieza. Al convertirse medio y obra en elementos indisociables, esta canalizará de forma lógica y natural este tipo de reflexiones. No obstante, en ocasiones esa auto-referencia implícita se ha forzado hasta hacerse explícita. Un ejemplo de ello se produce en Sonic Walkie, pieza en la que, recordemos, se registran los sonidos del espacio físico de Valencia y Manchester para mostrar paralelismos sonoros mediante, los cuales, las distintas ciudades del mundo se identificarían unas con otras. En una de sus pistas de audio titulada "Chat", se presenta como sonido identificativo el tecleo durante una conversación online y las alertas sonoras que indican que el usuario al otro lado de la línea ha contestado. Esta grabación obliga a concebir el paisaje sonoro urbano de forma distinta a la que tenía, por ejemplo, Henry en su obra La ville. Die Stadt: Metropolis Paris de 1984. Se impone, por tanto, una reflexión en torno al medio de Internet y a la infiltración de los fenómenos sonoros construidos a su alrededor en la vida acústica de las ciudades, de las que ya son parte indisoluble.

A lo largo de la exposición de ejemplos de net.sound art seleccionados para este artículo se observa, por un lado, sus relaciones estratégicas con prácticas de arte sonoro offline, y por otro, nuevas características estructurales vinculadas al medio. No obstante, ya se trate de una estructura cerrada, a modo de catálogo estanco en la que el usuario selecciona opciones predefinidas, o nos refiramos a una dinámica file-sharing en la que nuestras aportaciones pueden transformar las experiencias del resto de usuarios, Internet fomenta que sus habitantes abandonen la pasividad contemplativa para que se conviertan en productores y difusores de experiencias y/o datos. El sonido, conector de realidades, se ajusta con facilidad a las actividades de la Red favoreciendo la formación de puentes entre espacio y usuario, y/o entre 
usuarios. De la interactividad psicológica de la escucha "radiofónica” de Locustream Audio Tardis o The listening Machine, posible gracias a usuarios cómplices y twiteros respectivamente, pasando por la producción de composiciones fomentada por In $b$ flat 2.0 que, aunque en apariencia es solitaria, en realidad ha requerido de las voces instrumentales de numerosos cibercolaboradores, continuando con la experiencia social y de improvisación sonora transfronteriza de Daisyphone, prosiguiendo con la tipificación espacial a través de la identificación y comprensión sonora que facilitan Sonic Walkie y también, Locustream Audio Tardis gracias a la ubicuidad del medio, hasta la formación de un mapa social y colaborativo que actúa sobre espacios sonoros on y offline moldeándolos, el net.sound art adquiere multitud de formatos proporcionando experiencias híbridas y de interactividad variable a unos usuarios sobre los que, generalmente, recae la responsabilidad de mantener las obras vivas. Se debe insistir en que las características potenciadas por la pantallaInternet como "base de datos", "dinamismo", "datos en tiempo real" y "grados de interactividad" no son excluyentes, sino que se aplican tangencialmente según las necesidades de cada obra. Así pues, las posibilidades a la hora de cruzar variables de análisis vendrán siempre determinadas por la propia práctica artística, y nunca por la teoría.

Cabe destacar, que las nuevas competencias adquiridas en la Red por el arte sonoro, en ocasiones, pueden ser incompatibles con conceptos y taxonomías offline. Las distintas piezas de net.sound art y su particular relación con el medio dejan obsoletas, por ejemplo, las teorías excluyentes de los años setenta sobre la especificidad e inespecificidad del espacio de la instalación y la escultura sonoras. De la observación de este fenómeno, se ha propuesto en este artículo un nuevo concepto que definiría la relación entre una obra de arte concebida en, por y para la Red (es decir, específicas al medio) y el dinamismo de su espacio virtual (entorno estructuralmente inespecífico): el término site-flowing.

Internet es, definitivamente, un espacio prolífico para la producción de arte sonoro, albergando un amplio abanico de experimentos sonoros. Sin embargo, el sonido que generalmente relacionamos con la actividad de la Red es el tecleo físico producido en el espacio del cuerpo. Cabe destacar que, con el desarrollo de las pantallas táctiles que ya se utilizan habitualmente en móviles y tabletas y de las que se prevé su implantación en el ordenador personal, el sonido del tecleo corre el riesgo de desaparecer, al igual que lo hizo, en su día, el sonido de la máquina de escribir ¿Pero, introduzcámonos por completo en el ciberespacio, ¿Cuál es el ruido generado por su propia actividad virtual? El ciberespacio no se rige ni por la gravedad ni por ninguna otra ley física que origine fenómenos acústicos. No obstante, existen sonidos reconocibles por todo el globo que se asocian con el dinamismo de la Red. Nos referimos a los sonidos de las notificaciones de las distintas plataformas online como, por ejemplo: el correo electrónico, Whatsapp, 
Skype, Facebook, Pinterest, etc. Estas alertas que relacionan un sonido con un servicio concreto son el resultado del viaje de la información por un espacio virtual, y se originan en el momento en el que surge una conexión que, es importante aclarar, no solo puede deberse a la acción de un usuario, sino también a un programa automatizado. Por ello, la idea de Russolo de que donde hay ruido hay vida (VVAA, 2004), pilar fundamental para gran parte del arte sonoro, quizás debiera actualizarse, un siglo más tarde, para su aplicación en un ciberespacio que practica un "donde hay ruido hay conexión".

\section{REFERENCIAS}

Adorno, Theodor. L'art et les arts. Paris: Desclée de Brouwer, 2002 [1966].

Centre Ressources Labomedia. Une Histoire des arts numériques, des nouveaux medias, multimedia, interactif - de 1900 à nos jours. Última modificación junio 2014. Disponible en: http://wiki.labomedia.org [Consultado el 01 de junio de 2014].

Gómez, Bernabé. "Paralelismo diacrónico sobre la investigación sonora en el espacio de las artes plásticas", Arte y politicas de identidad: Entre el Arte sonoro y el Arte de la escucha Vol. 7 (2012): 29-50.

Howett, Catherine. "New Directions in Environmental Art", Landscape Architecture (1977): 38-46.

James, Richard. "Avant-Garde Sound-on-Film Techniques and Their Relationship to Electro-Acoustic Music", The Musical Quarterly 72 / 1 (1986): 74-89.

Jenkins, Henry. Convergence Culture. Where old and new media collide. New York: NYU Press 2006.

Kirn, Peter. "In Bb 2.0: YouTube-Generated, Collaborative Music Remix", Create Digital Music. 15 de Mayo 2009. Disponible en: http://createdigitalmusic. com/2009/05/in-bb-20-youtube-generated-collaborative-music-remix [Consultado el 06 de marzo de 2014].

Krauss, Rosalind. "Sculpture in the Expanded Field", October 8 (1979): 30-44.

Lévy, Pierre. Lintelligence collective : pour une anthropologie du cyberspace. París: Ed. La Découverte, 1997. 
Lippard, Lucy. "Art Outdoors, In and Out of the Public Domain", Studio International 193 (1977): 83-90.

Manovich, Lev. The Language of New Media. Cambridge, Mass.: MIT Press, 2001.

Robert, Philippe. Musiques Expérimentales. Une anthologie transversale d'enregistrements emblématiques. Marseille: Le mot et le reste, 2007.

Shaeffer, Pierre. Tratado de los objetos musicales. Madrid: Alianza Editora - Colección Alianza, 1988.

VV. AA. Ruidos y susurros de las Vanguardias. Reconstrucción de obras pioneras del Arte Sonoro (1909-1945). Valencia: UPV, 2004.

Worby, Robert. "Turn on, tune in: John Cage’s symphony for 12 radios", The Guardian. 6 de Agosto 2009. Disponible en: http://www.theguardian.com/music/2009/ aug/06/john-cage-symphony-for-radios [Consultado el 14 de febrero de 2014]. 